\title{
Postpartum family-planning barriers and catalysts in Burkina Faso and the Democratic Republic of Congo: a multiperspective study
}

This article was published in the following Dove Press journal: Open Access Journal of Contraception

\author{
Nguyen Toan Tran ${ }^{1-3, *}$ \\ Wambi Maurice E \\ Yameogo ${ }^{4,5, *}$ \\ Mary Eluned Gaffield' \\ Félicité Langwana ${ }^{6}$ \\ James Kiarie' \\ Désiré Mashinda Kulimba ${ }^{6}$ \\ Seni Kouanda ${ }^{4,5}$ \\ 'Department of Reproductive \\ Health and Research, World Health \\ Organization, Geneva, Switzerland; \\ ${ }^{2}$ Australian Centre for Public and \\ Population Health Research, Faculty \\ of Health, University of Technology, \\ Sydney, NSW, Australia; ${ }^{3}$ Institute of \\ Demography and Socioeconomics, \\ University of Geneva, Geneva, \\ Switzerland; ${ }^{4}$ Institut de Recherche en \\ Sciences de la Santé, Ouagadougou, \\ Burkina Faso; ${ }^{5}$ nstitut Africain de \\ la Santé Publique, Ouagadougou, \\ Burkina Faso; ${ }^{6}$ School of Public Health, \\ University of Kinshasa, Kinshasa, \\ Democratic Republic of Congo \\ *These authors contributed equally to \\ this work
}

Correspondence: Mary Eluned Gaffield Department of Reproductive Health Research, World Health Organization, 20 Avenue Appia, 121I Geneva 27, Switzerland

Tel +4 I 22 79| 4288

Fax +4| 22 79| 4857

Email gaffieldm@who.int
Purpose: To address the high unmet need for postpartum family planning (PPFP) in resourcelimited settings, particularly in sub-Saharan Africa, this study aimed to identify PPFP-related barriers and catalysts to inform policies and programs to increase access to postpartum contraception. Methods: Using qualitative methodology, we explored the perspectives of women, adolescent girls, men, religious and community leaders, service providers, and decision makers from three rural communities in Burkina Faso and three rural-urban communities in the Democratic Republic of Congo. Both countries have high unmet need for PPFP and are priority countries of the French Muskoka Fund for Maternal and Child Health

Results: Perceived catalysts included negative traditional views on the consequences borne by closely spaced children and their mothers; a 6-week postpartum visit dedicated to PPFP (albeit poorly attended); political will and enabling policies for FP; and support from certain religious leaders and men. Main reported barriers were the lack of male engagement; out-ofpocket copayment for contraceptives; reliance on amenorrhea for pregnancy prevention without knowing its limits; misconceptions about modern contraceptives, including prerequisites for the lactational amenorrhea method; sexual abstinence supported by religious and traditional norms for up to 3-6 months, although women reported earlier resumption of sexual activity; low prioritization of scheduled postpartum visits by women; and limited availability of readily accessible methods, PPFP counseling materials, and clinic days and scheduled visits dedicated to contraceptive services.

Conclusion: Based on results found to be most actionable, the following interventions have the potential to optimize access to PPFP services: counseling women on postpartum-pregnancy risks and options at different points in time before and after childbirth through the use of appropriate information, education, and counseling materials; integrating PPFP services into existing maternal and child health visits; making contraceptives readily available and affordable; and meaningfully engaging male partners.

Keywords: postpartum contraception, barriers, enablers, sub-Saharan Africa, Burkina Faso, Democratic Republic of Congo

\section{Plain language summary}

In developing countries, spacing pregnancies by at least 2 years could prevent poor health outcomes for mothers and infants, including death. After childbirth (postpartum), women in these settings, particularly in sub-Saharan Africa, have a highly unfulfilled need for effective family-planning (FP) methods. To inform policies and programs to increase access to postpartum FP (PPFP) services, our study aimed to identify enabling and impeding factors related to PPFP. 
To do so, we explored the perspectives of women, adolescent girls, men, religious and community leaders, service providers, and decision makers from rural and rural-urban communities in Burkina Faso and the Democratic Republic of Congo (DRC), two countries with high needs. Results indicated that negative traditional views on the consequences borne by closely spaced children and their mothers, a six-week postpartum visit dedicated to PPFP (albeit poorly attended), political will and enabling policies for FP, and support from certain religious leaders and men were perceived to be enabling factors for PPFP. Main reported barriers were lack of male engagement; out-of-pocket copayment for PPFP methods; reliance on nonreturn of menses for pregnancy prevention without knowing its limits; misconceptions about modern contraceptives, including prerequisites for the lactational amenorrhea method; sexual abstinence supported by religious and traditional norms for up to 3-6 months, although women reported earlier resumption of sexual activity; low prioritization of scheduled postpartum visits by women; limited availability of readily accessible methods, PPFP counseling materials, and clinic days and scheduled visits dedicated to contraceptive services. Based on the results we found most actionable, the following interventions have the potential to optimize access to PPFP services: counseling women on pregnancy risks after childbirth and options at different points in time before and after delivery through the use of appropriate information, education, and counseling materials; integrating PPFP services into existing maternal and child health visits; making contraceptives readily available and affordable; and meaningfully engaging male partners.

\section{Introduction}

Addressing the contraceptive needs of women after childbirth offers pivotal opportunities in health-service delivery to ensure that every woman and her family can enjoy the health, social, and economic benefits of family planning (FP). Spacing the birth-to-pregnancy interval by at least 2 years through effective postpartum contraception in less developed countries can prevent poor maternal, perinatal, and neonatal health outcomes, including stillbirth, prematurity, low birth weight, and neonatal and maternal mortality. ${ }^{1-3}$ The World Health Organization (WHO) describes postpartum FP (PPFP) as the prevention of unwanted pregnancies and closely spaced pregnancies during the first 12 months after delivery. ${ }^{4}$ During this period, pregnancy poses the greatest health threats to both mother and baby. ${ }^{5}$ Despite progress in access to reproductive, maternal, newborn, and child health (RMNCH) services in many sub-Saharan African countries in recent decades, advances in effective postpartum contraceptive use remain weak ${ }^{6-8}$ and the unmet need for postpartum contraceptive remains unacceptably high: according to estimates derived from Demographic Health Survey (DHS) data analysis from 57 countries during the 2005-2013 period and depending on the specific definitions of unmet need for PPFP, the proportion of women who no longer wanted children or wanted to postpone another child for at least 2 years after childbirth but were not using a contraceptive method ranged from $32 \%$ (at the end of amenorrhea) to $62 \%$ (soon after birth and before the sixth week postpartum). According to this prospective definition, which does not consider the protection granted by amenorrhea and abstinence, women should be offered a contraceptive method even during the amenorrheic state. ${ }^{9}$ Applying this prospective definition, the unmet need right after birth was $65 \%$ in eastern and southern Africa and even reached $75 \%$ in west and central Africa. The overall goal of our study is to address this high unmet need for PPFP.

Social, cultural, religious, and political norms and traditional practices have a critical influence on $\mathrm{RMNCH}$ and postpartum-pregnancy prevention. To be feasible, effective, acceptable, and sustainable, interventions aimed at increasing access to PPFP information and services need to take into consideration these norms, views, and practices, which have been little studied in sub-Saharan Africa. To gain insight into PPFP-related barriers and catalysts in this region, we focused our research on francophone west Africa and two of its countries with high unmet need for PPFP but limited research on the subject: Burkina Faso and the Democratic Republic of Congo (DRC). Both countries belong to the priority countries of the French Muskoka Fund for Maternal and Child Health, which supports this research.

In the DRC, there have been no published qualitative studies to draw from local norms, views, and practices to analyze barriers to and enablers of postpartum contraception. In Burkina Faso, qualitative study results examining traditional birth-spacing practices and uptake of PPFP among participants in the urban setting of its capital, Ouagadougou, offered the following insights: ${ }^{10}$ women did not view amenorrhea as prevention against pregnancy, and all initiated or planned to use a method just before or when they restarted sexual activity; abstention for half the women extended to $\geq 6$ months, and then some either adopted a method, which they used incorrectly, or did not adopt one at all; FP information and services were scheduled for the 6-week postpartum visit, which women rarely attended; and other reported barriers were providers' requirements that women initiating contraception be amenorrheic and husbands' refusal to refrain from unprotected sex. Perspectives 
on the subject from rural communities in Burkina Faso remain limited.

According to the most recent DHS data available from Burkina Faso (2010) and the DRC (2013-2014), the median duration of breastfeeding was 24 and 22 months, respectively (0.6 and 2 months for exclusive breastfeeding, respectively), median postpartum sexual abstinence 8 months in both countries, and median duration of amenorrhea 12 and 13 months, respectively. ${ }^{11,12}$ The median duration of birth intervals was 36 months in Burkina Faso and 31 months in the DRC, yet $13 \%$ and $27 \%$ of children, respectively, were born $<24$ months after their previous sibling. Most women in Burkina Faso (95\%) and the DRC (88\%) attended antenatal care (ANC) and delivered in a health facility ( $66 \%$ and $80 \%$, respectively). In Burkina Faso, $72 \%$ of postpartum women received postnatal care (PNC) within 48 hours of childbirth against $44 \%$ in the DRC, and $81 \%$ of children 12-23 months received all recommended vaccines compared with $41 \%$ in the DRC. Despite these contacts with health services in both countries, the unmet contraceptive need among postpartum women was high in Burkina Faso and the DRC: $89 \%$ and $66 \%$ right after birth, $50 \%$ and $48 \%$ after 6 months of amenorrhea, and $21 \%$ and $36 \%$ at the end of amenorrhea, respectively. The unmet need among all married women of reproductive age was also high (24\% and $28 \%$, respectively). ${ }^{9}$ In 2015, data from the World Bank showed for Burkina Faso and the DRC that the maternal mortality rate remained high $(371 / 100,000$ and 693/100,000 live births, respectively), as did the total fertility rate (5.4 and 6.2 , respectively).

To address these public health challenges, renewed efforts in both countries were made to implement integrated RMNCH programs. These included various initiatives, such as integrating FP and PPFP into national maternal and child health reference documents and services (eg, pilot projects on immediate postpartum intra-uterine devices [IUDs]; integrating training modules on PPFP into pre-service and in-service curricula for health professionals with the support of international nongovernmental organizations and United Nations agencies; ensuring national policy and program commitments toward Family Planning 2020; and reinforcing community-based services and distribution of contraceptives, including special campaigns to offer free FP services and methods (eg, "FP Week"). Another enabling factor for PPFP in both countries was linked to the introduction of performance-based financing, which aims to enhance the quality and productivity of health services.
For example, in Burkina Faso, several performance-based financing indicators are related to FP, including an indicator related to PPFP (number of postpartum women seen between days 6 and 8 and between weeks 6 and 8, the latter corresponding to the PPFP visit). However, in Burkina Faso and the DRC, contraceptive users must continue to copay for their methods.

Against this background, the objective of our study was to identify barriers and catalysts related to PPFP uptake with the participation of a range of stakeholders in Burkina Faso and the DRC. The resulting multistakeholder perspectives were part of the formative phase of a larger multipronged operational research intervention taking place in both countries: the Yam Daabo study ("your choice" in Mooré, the main local language in Burkina Faso). The overall objective of Yam Daabo was to determine the effectiveness of a context-sensitive intervention package on the uptake of contraceptive methods during the first year postpartum in Burkina Faso and the DRC. We assumed that to be effective in increasing the uptake of contraception during the first year postpartum, the development of such a package should be based upon meaningful engagement of various stakeholders in the research process, including women, adolescent girls, men, religious and community leaders, service providers, and public health and healthservice decision makers, on top of being cost-effective We recently published the research protocol of the Yam Daabo study, ${ }^{13}$ and aim with this paper to describe the identification and analysis of barriers and catalysts related to PPFP as perceived by key stakeholders. The study was implemented between September and October 2015 in collaboration with national research teams: the Health Sciences Research Institute/Institut de Recherche en Sciences de la Santé in Ouagadougou, Burkina Faso, and the School of Public Health/Ecole de Santé Publique of Kinshasa University, DRC.

\section{Methods \\ Study sites}

In each country, we carried out the research in three health centers at the primary-care level and their respective coverage areas. These centers were conveniently drawn from a sampling frame established at the beginning of the study. The sampling frame was based on the mapping of study sites from a rural area in Burkina Faso and from a rural-urban area in the DRC where there has been no PPFP research or intervention in the past. To be eligible, 
study sites had to 1) offer the continuum of ANC, delivery, and $\mathrm{PNC}$; 2) provide a selection of at least three modern contraceptive methods, including a barrier method, such as condoms, a short-term method, such as pills, a long-term method, such as IUDs and referrals for permanent methods to clients; 3 ) have had no contraceptive stock-out during the preceding 6 months; 4) perform on average at least 30 deliveries per month; 5) be situated within 4 hours' drive from the research center; and 6) be willing to participate. The selected sites were situated in the province of Yako, Burkina Faso (communes of Bokin, rural; Latoden, rural; and Yako, urban) and in the province of Kinshasa, the DRC (districts of Nsele, rural; Kimbanseke, urban; and Bumbu, urban). With regard to the availability of at least three contraceptive methods and no contraceptive stock-out during the preceding 6 months, there is obvious evidence that these factors have an impact on modern contraceptive uptake. Therefore, these factors were controlled during the experimental phase of Yam Daabo by ensuring that study sites in both intervention and control arms of the clusterrandomized controlled trial fulfilled these criteria. These criteria were, however, not a departure from field reality, as both Burkina Faso and the DRC had recently made substantial progress in this area. ${ }^{14,15}$

\section{Participants}

We used predetermined criteria that are described hereafter purposefully to sample women, partners, and service providers who were recruited from the health centers and approached face to face. In total, we led 22 separate focusgroup discussions (FGDs; 13 in Burkina Faso and 9 in DRC) of six to ten participants (total participants 124 in Burkina Faso and 89 in DRC) for the following categories of individuals: 1) women who were currently pregnant or who had delivered at the health center during the previous 12 months, with age determining allocation to subgroups (adolescents [ $\leq 19$ years], women [20-39 years], and women [ $\geq 40$ years $]$ ); 2 ) men ( $25-40$ years) who were current partners or husbands of women who were pregnant or who had delivered at the health center during the previous 12 months (these women could be those recruited under category 1 or other women with such characteristics); and 3) service providers (auxiliary midwives [commonly employed in RMNCH services at the primary-care level], midwives, nurses, and doctors). We held 34 in-depth interviews (IDIs; 21 in Burkina Faso and 13 in DRC) with purposefully identified informants: heads of health centers or maternity services, stakeholders from United Nations agencies (ie, WHO, UNICEF, UNFPA) and the Ministry of Health, and individuals whom local informants had identified in each recruitment zone as influential (ie, religious leaders, village or neighborhood chiefs, traditional practitioners, community health workers). IDIs were more suitable for this latter category of participants, mainly due to their hierarchical position at work or in the community. Table 1 reports the number of FGDs and IDIs by type of informant. Adult participants gave informed consent. Nonadult participants gave informed assent and their respective parents or guardians informed consent.

\section{Data collection}

We prepared the semistructured FGD and IDI guides in French. In each country, a team of social scientists speaking the respective local languages (Mooré in Burkina Faso and Lingala in the DRC) conducted the interviews after being trained in finding the clearest and most appropriate language to express technical terms in the local languages. The interviews were conducted in a location guaranteeing privacy and audio-taped after obtaining agreement from participants. Those not agreeing to be recorded were excluded from the study.

Table I Focus-group discussions and in-depth interviews by type of informant in Burkina Faso and the Democratic Republic of Congo (DRC)

\begin{tabular}{|c|c|c|}
\hline & Burkina Faso & DRC \\
\hline & \multicolumn{2}{|c|}{ Focus-group discussions } \\
\hline Women $\leq 19$ years & 3 & 2 \\
\hline Women $20-39$ years & 3 & 2 \\
\hline Women $\geq \mathbf{4 0}$ years & 3 & 2 \\
\hline Partners/husbands & 3 & 3 \\
\hline Service providers & 1 & 0 \\
\hline Total & $\begin{array}{l}\text { I3 } \\
\text { In-depth inter }\end{array}$ & $\begin{array}{l}9 \\
9\end{array}$ \\
\hline Community health worker & 2 & 0 \\
\hline Head of health center/maternity & 3 & 3 \\
\hline Traditional practitioner & 0 & I \\
\hline Village/neighborhood chief & 3 & 2 \\
\hline Religious leader & & \\
\hline Christian faith & 7 & I \\
\hline Islam & 4 & 0 \\
\hline United Nations agency & I & 3 \\
\hline Nongovernmental organization & I & 2 \\
\hline Ministry of Health & 0 & $\mathrm{I}$ \\
\hline Total & 21 & 13 \\
\hline
\end{tabular}




\section{Data management and analysis}

Research assistants translated the audio records into French and transcribed them into Microsoft Word. Accuracy checks of Word files were done by comparing transcripts with audio files. We performed a thematic analysis using QSR NVivo 10, qualitative research-management software. We established a basic codebook to describe all the nodes and used it to code data. We enriched the codebook with new emerging nodes during the coding process. To ensure the quality of data coding, we performed interrater reliability testing by computing Cohen's $\kappa$-coefficient. We considered $\kappa \geq 0.8$ to be an acceptable concordance threshold. We categorized the data into matrices according to themes. The study results are thus presented according to the main themes. Each theme may cover perspectives on both barriers and/or catalysts.

\section{Ethical approval}

The research protocol was approved by the Research Project Review Panel (RP2) of the UNDP/UNFPA/UNICEF/WHO/ World Bank Special Programme of Research, Development and Research Training in Human Reproduction at the WHO in Geneva and the WHO Research Ethics Review Committee, Geneva, Switzerland. The study was approved by the respective ethical committees of Burkina Faso and of the DRC. It was registered in the Pan African Clinical Trials Registry (PACTR201609001784334) and is reported according to the COREQ requirements. ${ }^{16}$

\section{Results}

\section{Birth spacing and fertility intention}

In both countries, the ideal time between two pregnancies was reported to be a minimum of 2 years, so that "the mother can recover, and the child has a chance to grow well" (religious leader, DRC). Closely spaced pregnancies were perceived negatively by most participants: specific terms exist in both countries to describe children who are born in a short time frame after each other. In the DRC, they are called kilandi (literally "successor") in Kikongo, one of the national languages, and in Burkina Faso pondssé in Mooré (literally a child who is not old enough to have a younger sibling):

Kilandi ... suffer from lack of love and affection. They are nervous and always sick. [service provider, DRC]

Pondssé-là . . . will be very small . . . it's not a good thing. It will not only tire the woman but also prevent her from recovering and getting back into shape. [village chief, Burkina Faso]
The specific terminology may be linked to the fact that such children are perceived to endure emotional and physical suffering, in addition to being a burden for their mother, who might be negatively perceived by the community because she "should not have children as ducks spread droppings everywhere" (women aged 20-39 years, DRC).

While young and old women, men, and influential community members appeared largely to agree on the importance of limiting family size, the reported number of desired children remained nonetheless high, ranging from five to seven or more:

I think that a woman should have five or six children. [women aged 20-39 years, Burkina Faso]

She can only have two or three children, if [these are born] by cesarean section. But if she gives birth normally, she can go to seven [children]. [woman aged $\leq 19$ years, DRC]

\section{Awareness of pregnancy risk and contraceptive adoption}

Pregnancy risk being mainly associated with the return of menses was a widely shared view among all stakeholders:

After the return of menses, the woman can get pregnant again if one does not use birth-spacing methods or does not respect the calendar. [women aged $\geq 40$ years, DRC]

The return of menses could occur at different points in time depending on women's "fertility". However, according to several interviewed religious and community leaders, intercourse should be delayed by 3-6 months postpartum, so that women could enjoy a period of "natural rest". However, discussions with both younger and older women suggested that this abstinence period of several months may not be respected. As a result, pregnancy could occur much earlier (after menses return), as reported by women aged $\leq 19$ years or under in Burkina Faso:

- [Getting pregnant], it's after a month [postpartum].

- It's after 2 months.

- It depends on the woman. You can get pregnant even after a week. [women aged $\leq 19$ years, Burkina Faso]

For many women, the time to start a contraceptive method was at "6 weeks" or "40 days" after birth, which was an opinion commonly shared by men. This also corresponded with the recommended national guidance in both countries. For other women, the time of PPFP adoption was when menses return, and for a few directly after childbirth. In both 
countries, women appeared to be aware of different modern contraceptives. The most commonly reported methods were injectables, pills, implants, and male condoms. The lactational amenorrhea method (LAM), IUDs, and female condoms were the least mentioned, although Congolese women were more aware of the LAM than Burkinabé women.

\section{Misconceptions about contraception}

Health professionals appeared knowledgeable about modern contraceptives and its use in the postpartum period. This contrasted with the negative perceptions reported by women and men in both countries about contraception, although there was limited specific mention of PPFP. For some men, preventing pregnancy by modern contraceptives was compared to "killing a human being" whose incarnation could be rendered difficult and women using contraceptives were potentially unfaithful and could make men sick in different ways, including by absorbing the heat that these women would generate:

There are women using family planning who have swelling of their feet, and when you sleep with them they generate a certain heat inside their body. If you receive that heat two or three times, you can fall sick, and when you get tested, people cannot even know what disease you suffer from. [men, Burkina Faso]

As for women, rumors, misconceptions, or direct experience influenced their negative views on modern contraceptives, which included risk of irregular menses, infertility, diabetes, weight gain, high blood pressure, or other diseases thought to be caused by specific methods. When asked about the LAM, women displayed incredulity about the pregnancy protection it could offer (which also points to the use of abstinence to deal with PPFP needs), as illustrated by an FGD in the DRC with women aged $20-39$ years:

- No way.

- We do not know. But is it really possible?

- . . what we know how to do is to breastfeed a child.

But not getting pregnant thanks to breastfeeding: Is it feasible?

- . . it's not possible without really God's help. It's not possible! One has to only run away from men ... [women aged 20-39 years, DRC].

\section{Financial barriers}

Although the price of contraceptive methods could vary according to what women could afford and was considered reasonable by policymakers, many users, as well as service providers and community stakeholders, reported that the cost, even "insignificant" for some methods, constituted a major barrier. Some women started a short-term method, but had to discontinue its use because they could no longer afford it:

Some women get pregnant because of CFA250 [USD 0.45].

Some come to tell you that they want contraception, but they do

not have the money. [service providers, Burkina Faso]

Providers agreed that implants or IUDs were relatively more costly than short-term methods, and women who could not afford them tended not to use any and to wait for the national FP Week or other campaigns when methods and services would be offered free of charge.

\section{Religious considerations}

Religious traditions are different in the study settings (Islamic and Christian in Yako, Burkina Faso; Christian in Kinshasa, the DRC) and were perceived as both enabler and hindrance as regards FP. For instance, the Union of Religious and Traditional Leaders of Burkina Faso for Health Promotion and Development has been supporting several FP-promotion programs since 2011. Others supported birth spacing, but did not always favor contraceptive use, which was described by a religious leader in Burkina Faso as a form of "disobedience to the word of God". Some contraceptives, such as implants, or at least their side effects, were seen to prevent "our women from being regular in their prayers", due to the prolonged bleeding, which they reported to be incompatible with prayers.

On the other hand, providers and community leaders in the DRC mentioned that certain churches supported FP and helped promote its benefits, as contraceptive methods were the "work of God who gave mankind the intelligence [to use it]". Information, education, and counseling about birth spacing appeared to have an influence in weakening religious barriers against it:

Before, religion forbade it. But now, those who have an understanding accept it. When one talks about birth spacing, people do not want it. They say that children are a gift of God. But now, with counseling, they accept. [women aged 20-39 years, DRC]

\section{PPFP-service provision}

In Burkina Faso and the DRC, women seemed to know about the 6-week PPFP postpartum visit. Postpartum women did not appear to comply with this recommended scheduled visit, as suggested by providers in Burkina Faso in the following terms: 
For postpartum family-planning visits, the proportion is very low. Women do not come during the postpartum. But if it's a visit for the infant, then they all come ... [Women] tell themselves that once they have given birth, it's over and they have no reason to come ... It's the community health worker who does outreach visits who has to catch up with them at home. [service providers, Burkina Faso]

The research team observed during visits to the study sites that not all methods were offered (eg, most centers employed auxiliary midwives who were not trained to provide IUDs), contraceptive services were generally available only during certain days or half-days of the week, service providers did not seem to offer PPFP information during ANC, right after childbirth, or PNC, and that there were no dedicated PPFP job aids or counseling tools. However, a minority of providers were of the view that not offering PPFP information to "a pregnant woman during her third trimester, in the delivery room when she labors, and after childbirth" was a missed opportunity during these contact points between women and providers.

In Burkina Faso, women who choose a method must purchase it from the medicine "stock house" at the clinic. Stock houses were reported to have limited opening hours and to be managed by community members. Women and providers expressed the concern that the lack of contraceptive supplies readily available from providers when they needed it was not conducive for confidential and accessible services, especially if women wished to use a method right after birth. The national FP weeks in Burkina Faso and the DRC were seen by all interviewees as unmatched opportunities to access free contraceptive information and services, especially longacting reversible contraceptives.

\section{Women's empowerment, male engagement, and contraceptive decision- making}

A lack of male engagement and absence of interventions that specifically targeted them were found across sites to be a key barrier to PPFP programs. A woman in the DRC asserted that "our husbands are the problem", which summarizes the general sentiment of women about men as main barriers to FP and PPFP: some men perceived contraception as a mean of murder (“... avoiding a pregnancy is like murdering a human being" [men, Burkina Faso]) or infidelity, were described as the ultimate decision makers of the household, and could become violent if they happened to know that their spouse was using contraception without their consent.

If my husband sees me [at the health center], he will think that I came here to look for a birth-spacing method, and tonight he will beat me. [women aged 20-39 years, DRC]

... The man thinks that the woman using contraception will rest. However, if one hears that she wanders around because she knows she cannot get pregnant, there begins trouble ... [male village chief, Burkina Faso]

Both decide together [about contraception]. But most of the time, women start discussing about it with their husbands, because women are those who suffer and initiate the use of family planning. But in the end, husbands are those deciding whether or not the woman can use family planning. [male religious leader, Burkina Faso]

Some women had recommendations for our research team along these lines:

I think that you must first sensitize men about birth spacing and family well-being before coming to women, because women are not free. [women aged $\geq 40$ years, Burkina Faso]

Although most men accompanied their partners to the health facility for childbirth and fetched them back home afterward, they did not usually attend the birth of their child or subsequent postpartum checks. For men who agreed to their spouses using contraceptives, they viewed their presence at the clinic and during FP visits as potentially stigmatizing and even girly ("femmelette"). However, some men expressed the desire to be engaged in PPFP programs but were put off by a health system that "invests more on women" and "does nothing for the moment (for them)":

I think that it is necessary to provide family-planning information to men, because it is the lack of knowledge that causes many men not to want their wives to do family planning." [religious leader, Burkina Faso]

It is important to note what was not discussed in interviews with men: no one mentioned the use of male contraceptives.

Although male engagement was still lacking and decision-making not only about contraception but also sexual intercourse did not lie in women's hands, providers in Burkina Faso mentioned the importance of no longer needing the husband's formal agreement before offering contraceptive services to women. Many women in both countries reported overriding their partners' refusal by hiding their FP visits: 
Men who have not yet understood [the importance of family planning] will not even listen to you, which will encourage some women to hide to do it [get contraceptives]. If you do not do it, you will suffer: you will make babies like mice do, and you will suffer as a result: men will go out and leave you alone ... [women aged $\geq 40$ years, Burkina Faso]

\section{Discussion}

Multiple stakeholders across rural communities in Burkina Faso and rural-urban communities in the DRC offered useful but in general unsurprising insights into PPFP barriers and enablers. These insights could inform policies and programs to address women's and couples' unmet needs for PPFP. Despite the difference in countries and community settings, we were struck by the fact that results from both countries were not dissimilar, which allowed their categorization into shared themes. The results align with those of other studies conducted in sub-Saharan Africa on contraception. ${ }^{17}$ The main difference with the PPFP study in Ouagadougou ${ }^{10}$ is that women in our study appeared to view amenorrhea as prevention against pregnancy, although other women reported that the right time to start a contraceptive method was at 6 weeks after childbirth, which is in general before the resumption of menses. The limited contrast in points of view between rural Burkinabé and urban Congolese women and men may be explained by the social and economic underdevelopment of the communities sampled from the province of Kinshasa, where poverty, hunger, and underdevelopment remain critical challenges. ${ }^{18}$ The social and economic underdevelopment combined with limited educational opportunities and deeply rooted cultural norms common in both settings may also have contributed to leveling out the diversity of perspectives expected from women of different age groups. We acknowledge that results could have been skewed by the selection criteria of health centers and sampling of participants, particularly of women who had to attend ANC or give birth in these facilities. Women who did not attend ANC or those who gave birth at home (albeit a minority in both countries) may have provided different perspectives. Because one of Yam Daabo's working hypotheses regarding the intervention package was to strengthen existing ANC and PNC services in primary health care centers, we purposely sampled women who had attended these services.

While views about abstinence, pregnancy risks, timing of contraceptive adoption, LAM, and provision of postpartum contraceptive services are unique to PPFP, others, such as on modern contraceptives or male engagement, pertain to FP and $\mathrm{RMNCH}$ in general. The enabling policy environment for
PPFP in both countries echoes the PPFP Global Movement that was initiated in 2015 to accelerate PPFP policies and programs in the footsteps of Family Planning 2020. Supportive FP policies and effective FP programming integrating postpartum contraception could positively influence the healthy timing and spacing of children. It could also reduce the desired family size of five and more children reported in both countries (as in other sub-Saharan countries), for which a decrease would require not only sustained development gains but also strong investment in national FP programs. ${ }^{19}$

Despite the favorable policy environment, women in each country still needed to bear the costs of contraceptive services, which were perceived to be a barrier to PPFP uptake. Based on our field observation, in the DRC, the approximate cost in USD was 0.70-2.00 for 3-month injectables, 2.00-5.00 for implants, 1.20-3.20 for IUDs, and generally free for pills and male condoms. In Burkina Faso, the approximate cost in USD was 0.50-1.00 for 3-month injectables, 1.00-2.00 for implants, 1.00-2.00 for IUDs, 0.45-0.60 for a 3-month supply of pills, and 0.02 per male condom. Stakeholders were appreciative of the free services offered during the national FP weeks, but their periodic occurrence once or twice yearly may not be timely for women who wish to start an effective method at a given moment in the postpartum period. The costs of health services are subsidized in both countries. However, out-of-pocket copayment for ANC, childbirth, PNC, and contraceptive services (and in particular long-acting reversible contraceptives) in a short period could deter women from resource-constrained households from adopting a modern method. In April 2016, Burkina Faso implemented a policy of free childbirth and care to children aged $<5$ years to increase access to attended deliveries and improve RMNCH outcomes. As contraceptives are recognized as a highly cost-effective intervention in RMNCH, such policy should be extended to cover free FP services (or at least during the first year postpartum) to remove financial barriers to the uptake of modern contraceptives effectively.

The terminology for children born too closely is crystallized in specific terms in Mooré and Lingala and indicates how society negatively perceives the consequences borne by such children and their mothers. This contrasts with the gaps in knowledge and practices of women and men about pregnancy risks after childbirth and how to mitigate these risks effectively.

Most participants linked pregnancy risk with the return of menses. Demand for effective contraception postpartum was shown to be limited by the reliance on amenorrhea for pregnancy prevention, abstinence from sex for long periods 
after childbirth, and the prevailing behavior of women adopting modern contraceptives only when sexual activity or menses resumed. ${ }^{20}$ An analysis of four countries indicated that women relied on postpartum amenorrhea as a traditional PPFP method without knowing its limitations, especially in sub-Saharan Africa, where they were generally breastfeeding their babies for up to 2 years (although not exclusively). ${ }^{21}$

The length of postpartum amenorrhea depends on breastfeeding practices. A systematic review concluded that for women who were not breastfeeding, pregnancy could occur within 45 days postpartum even before the return of menses. ${ }^{22}$ According to Kennedy and Visness, who pooled data from nine prospective studies from low- and high-income countries, the LAM carried a low risk of pregnancy $(\leq 2 \%) .{ }^{23}$ Among breastfeeding women who remained amenorrheic (regardless of supplementary feeding), this risk increased only slightly to $3 \%$ at 6 months and $6 \%$ at 12 months. These pregnancy risks are similar to those of modern contraceptive methods. This contrasts with a study in rural Egypt showing that in women who reported to be exclusively or almost exclusively breastfeeding, around a quarter (28\%) were at risk of pregnancy before 6 months postpartum, because most of them did not meet the requirements for the LAM. ${ }^{24}$

While promoting the LAM for up to 6 months before transitioning to another modern method appears justified from an $\mathrm{RMNCH}$ perspective, as presented in the Introduction, very low levels of exclusive breastfeeding in Burkina Faso and the DRC are not encouraging and reflect the situation in other low-income countries. ${ }^{25}$ Early supplementation practices rooted in traditions may explain these low levels of exclusive breastfeeding. The median duration of amenorrhea of around 12 and 13 months reported in DHS surveys in both study countries suggests that breastfeeding, although not exclusive, must be sufficiently frequent to produce an amenorrheic state. Consequently, having providers repeatedly counsel women on the LAM may not be efficient in these resource-constrained study settings. However, service providers should counsel women properly on pregnancy risk after childbirth and the risk of relying on amenorrhea alone for pregnancy prevention. Counseling should also address general misconceptions about modern contraceptives and lack of knowledge about the LAM that is reported in our study and other low-income countries. ${ }^{26}$ For women interested in adopting the LAM, providers should counsel them about its noncontraceptive benefits (eg, best nutrition for infants aged $<6$ months) and contraceptive advantages. LAM prerequisites need to be taught correctly to women who opt for it, stressing the importance of using other modern contraceptives when these prerequisites are no longer fulfilled.
In terms of the appropriate timing of contraceptive uptake, women in our study mentioned a range of possibilities (when menses returned, at 6 weeks, or directly after childbirth for a few). Our study missed the opportunity to probe women about their willingness to adopt a contraceptive method before the return of menses. However, a multicountry analysis that did not include our study countries showed that $29 \%$ of all women adopted a modern method before the return of menses. ${ }^{27}$

Our study did not bring to light who in the couple controlled the resumption of sex. A qualitative study in Côte d'Ivoire reported that men usually made the first move to resume sex, although timing was negotiated by women. ${ }^{28}$ This finding is indirectly corroborated by our results, whereby women lacked the necessary empowerment to make decisions about sex and contraception.

Our analysis suggests sexual abstinence to be supported by religious and traditional norms for up to 3-6 months. Such extended periods may not correspond to the reality of women in our study, who indicated earlier resumption of sexual activity, which contrasts with findings from other studies in west and east Africa. ${ }^{10,20}$ However, a survey of 374 postpartum women in Uganda showed that around one in five reported resumption before 6 weeks after childbirth (women who did so had low parity, higher income, a spouse with high education level, and had previously used contraception). ${ }^{29}$ Likewise, in Nigeria, where long postpartum-abstinence periods are culturally valued, the median time of intercourse resumption (which was mainly initiated by husbands) was reported in two studies done in two different regions to be 6-12 weeks postpartum..$^{30,31}$ Therefore, the timing of the 6-week PPFP appointment may not fit the needs of women who wish to transition from abstinence earlier or later than 6 weeks after childbirth. Visits at different times before and after childbirth may give women more opportunities to get counseled on PPFP options that match their unique circumstances.

In this respect, according to the published literature, different interventions along the ANC-childbirth-PNC continuum may have a positive effect on postpartum contraceptive uptake: 1) counseling activities in ANC; ${ }^{32-36} 2$ ) access to contraceptive methods immediately after childbirth; ${ }^{37-39} 3$ ) provision of PPFP information, education, and counseling materials before the woman is discharged home from the health facility, including the advanced provision of emergency contraception backup to LAM users, in case one of the prerequisites of the LAM has expired and sex has occurred before the initiation of another modern method;40-43 4) longer programs with several contact points between providers and clients across the continuum of care (eg, ANC and PNC) 
vs punctual interventions; ${ }^{44-46}$ and 5) integration of PPFP into immunization and child-health services that may yield positive results, but programmatic challenges (eg, provider competence, time pressure, and competition with other priority interventions) and policy barriers remain. ${ }^{47-51}$

Our study highlights several issues related to access to PPFP information and services. Contraceptives should be made readily available by providers to ensure privacy and confidentiality without resorting to purchasing them from a stock house managed by community members. PPFP services should not be limited to certain days of the week and only offered once during the 6-week postpartum period. Access to a wide range of methods, including IUDs, should be ensured by offering FP-refresher courses or training to auxiliary midwives who staff most of the rural or suburban health centers.

We have described earlier various integration approaches. In addition, strategies should be developed with women, community members, and service providers on the best way to encourage women to demand PPFP services. A counseling tool dedicated to PPFP stressing the benefits and means of birth spacing, and tackling misconceptions about modern contraceptives would support both providers and their clients in choice-based and informed discussions on PPFP.

While some religious leaders expressed concerns about contraception, others were supportive. The women we interviewed, however, did not seem to identify religious considerations as an impediment to accessing contraception. The major challenge came from men, which corroborated findings from other studies showing that RMNCH-related decision-making was not in women's hands - in both west and central Africa, one in five women reported this barrier. ${ }^{9}$ The fact that we managed to recruit men to discuss PPFP may signal that some shift was already happening. In fact, we were surprised that some men even asked that programmatic efforts be deployed to target men. Engaging men is a stepping stone to ensure that women and couples are supported in their PPFP choice and continued use of an effective method that match their needs.

\section{Conclusion}

In consideration of social, cultural, religious, and policy challenges and opportunities regarding contraception, a multistakeholder approach resulted in the identification of PPFP barriers and catalysts. Designing interventions that account for barriers and catalysts necessitates balancing continued engagement with key stakeholders with activities that are actionable. For instance, actionable activities could include counseling women on postpartum-pregnancy risks and safe contraceptive options prior to and following child- birth, assuring that PPFP services are integrated into existing maternal and child-health visits, making contraceptives available and affordable, and meaningfully engaging male partners. Involving key stakeholders could result in the design of a package of PPFP interventions that responds to the needs of communities, upholds rights-based principles, aligns with national policies, and acknowledges the scarcity of local resources. Such an intervention package would guide a more systematic discussion of birth-spacing options between providers and their clients and a timely provision of quality postpartum-contraceptive services.

\section{Ethics approval and consent to participate}

The research protocol was approved by the Research Project Review Panel (RP2) of the UNDP/UNFPA/UNICEF/WHO/ World Bank Special Programme of Research, Development, and Research Training in Human Reproduction (HRP) at the WHO in Geneva and the WHO Research Ethics Review Committee, Geneva, Switzerland. The study was approved by the ethics committees of Burkina Faso (Comité d'Ethique pour la Recherche en Santé, Ministère de la Santé and Ministèrede 1'Enseignement Supérieur de la Recherche Scientifique et de l'Innovation, reference 2016-02-019) and the DRC (Comité d'Ethique, Ministère de l'Enseignement Supérieur et Universitaire, Université de Kinshasa, Ecole de Santé Publique, reference ESP/CE/039b/2016). All adult participants provided written consent. Nonadult participants gave their informed assent and their respective parents or guardians their informed consent.

\section{Abbreviations}

ANC, antenatal care; DRC, Democratic Republic of Congo; FGD, focus-group discussion; FP, family planning; IDI, indepth interview; IUD, intrauterine device; LAM, lactational amenorrhea method; PBF, performance-based funding; PNC, postnatal care; PPFP, postpartum FP; RMNCH, reproductive, maternal, newborn, and child health; WHO, World Health Organization.

\section{Data sharing statement}

Data are available upon request.

\section{Acknowledgments}

Work on this research project was initiated within the WHO Department of Reproductive Health and Research (RHR). The Government of France generously provided funding for this research grant in the context of the Muskoka Initiative on Maternal and Child Health. We are thankful to Asa Cuzin-Kihl for 
the overall coordination of the project and her technical input, and to Suzanne Reier for coordinating talks with donors and partners and for contributing to the initial design of the study.

\section{Author contributions}

NTT and MEG conceived the initial study concept and designed the study protocol and study instruments. SK, WMEY, DMK, and FL contributed to the final study protocol and study instruments. NTT and WMEY wrote the manuscript, with contributions from SK, MEG, FL, JK, and DMK. All authors contributed toward data analysis, drafting and revising the paper, gave final approval of the version to be published, and agree to be accountable for all aspects of the work.

\section{Disclosure}

The authors report no conflicts of interest in this work.

\section{References}

1. Conde-Agudelo A, Rosas-Bermúdez A, Kafury-Goeta AC. Effects of birth spacing on maternal health: a systematic review. Am J Obstet Gynecol. 2007;196(4):297-308.

2. Conde-Agudelo A, Rosas-Bermúdez A, Kafury-Goeta AC. Birth spacing and risk of adverse perinatal outcomes: a meta-analysis. JAMA. 2006;295(15):1809-1823.

3. Cleland J, Bernstein S, Ezeh A, Faundes A, Glasier A, Innis J. Family planning: the unfinished agenda. Lancet. 2006;368(9549):1810-1827.

4. World Health Organization. Programming Strategies for Postpartum Family Planning. WHO, Geneva; 2013.

5. Davanzo J, Hale L, Razzaque A, Rahman M. Effects of interpregnancy interval and outcome of the preceding pregnancy on pregnancy outcomes in Matlab, Bangladesh. BJOG. 2007;114(9):1079-1087.

6. Ross JA, Winfrey WL. Contraceptive use, intention to use and unmet need during the extended postpartum period. Int Fam Plan Perspect. 2001;27(1):20-27.

7. Adeyemi AB, Ijadunola KT, Orji EO, Kuti O, Alabi MM. The unmet need for contraception among Nigerian women in the first year postpartum. Eur J Contracept Reprod Health Care. 2005;10(4):229-234.

8. Moore Z, Pfitzer A, Gubin R, Charurat E, Elliott L, Croft T. Missed opportunities for family planning: an analysis of pregnancy risk and contraceptive method use among postpartum women in 21 low- and middle-income countries. Contraception. 2015;92(1):31-39.

9. Rossier C, Bradley SE, Ross J, Winfrey W. Reassessing unmet need for family planning in the postpartum period. Stud Fam Plann. 2015;46(4):355-367.

10. Rossier C, Hellen J. Traditional birthspacing practices and uptake of family planning during the postpartum period in Ouagadougou: qualitative results. Int Perspect Sex Reprod Health. 2014;40(2):87-94.

11. Institut National de la Statistique et de la Démographie (INSD) et ICF International. Enquête Démographique et de Santé et Indicateurs Multiples du Burkina Faso 2010. Calverton, MD, USA: INSD et ICF International; 2012.

12. Ministère du Plan et Suivi de la Mise en ouvre de la Révolution de la Modernité (MPSMRM), Ministère de la Santé Publique (MSP) et ICF International. Enquête Démographique et de Santé en République Démocratique du Congo 2013-2014. Rockville, MD, USA: MPSMRM, MSP et ICF International; 2014.

13. Tran NT, Gaffield ME, Seuc A, et al. Effectiveness of a package of postpartum family planning interventions on the uptake of contraceptive methods until twelve months postpartum in Burkina Faso and the Democratic Republic of Congo: the YAM DAABO study protocol. BMC Health Serv Res. 2018;18(1):439.
14. Track20 Project. Available from: http://www.track20.org/pages/participating_countries/countries_country_page.php?code=BF. Accessed July 4, 2018.

15. Kayembe P, Babazadeh S, Dikamba N, et al. Family planning supply environment in Kinshasa, DRC: survey findings and their value in advancing family planning programming. Glob Health Sci Pract. 2015;3(4):630-645.

16. Tong A, Sainsbury P, Craig J. Consolidated criteria for reporting qualitative research (COREQ): a 32-item checklist for interviews and focus groups. Int J Qual Health Care. 2007;19(6):349-357.

17. Campbell M, Sahin-Hodoglugil NN, Potts M. Barriers to fertility regulation: a review of the literature. Stud Fam Plann. 2006;37(2):87-98.

18. Longondjo C. Urbanization and Poverty in Kinshasa: Thinking Beyond 2015 Millennium Development Goals. Millennium Development Goals (MDGs) in Retrospect. Springer, Zug; 2015:31-44.

19. Bongaarts J. Can family planning programs reduce high desired family size in Sub-Saharan Africa? Int Perspect Sex Reprod Health. 2011;37(4):209-216.

20. Ndugwa RP, Cleland J, Madise NJ, Fotso JC, Zulu EM. Menstrual pattern, sexual behaviors, and contraceptive use among postpartum women in Nairobi urban slums. J Urban Health. 2011;88(Suppl 2):S341-S355.

21. Gebreselassie T, Rutstein SO, Mishra V. Contraceptive use, Breastfeeding, Amenorrhea and Abstinence during the Postpartum Period: An Analysis of Four Countries. Calverton, Maryland, USA: The DHS Program; 2008 August.

22. Jackson E, Glasier A. Return of ovulation and menses in postpartum nonlactating women: a systematic review. Obstet Gynecol. 2011;117(3): $657-662$.

23. Kennedy KI, Visness CM. Contraceptive efficacy of lactational amenorrhoea. Lancet. 1992;339(8787):227-230.

24. Shaaban OM, Glasier AF. Pregnancy during breastfeeding in rural Egypt. Contraception. 2008;77(5):350-354.

25. Fabic MS, Choi Y. Assessing the quality of data regarding use of the lactational amenorrhea method. Stud Fam Plann. 2013;44(2): 205-221.

26. Fabic M, Choi Y. Measuring use of the lactational amenorrhea method through the Demographic and Health Surveys: data quality and implications. Paper presented at: annual meeting of the Population Association of America, New Orleans: 2013

27. Ali MM, Shah IH. Uptake of contraception following childbirth or pregnancy termination: A preliminary analysis. Paper presented at the Annual Meeting of the Population Association of America, 1-3 April 2004. Boston, MA.

28. Desgrées-du-Loû A, Brou H. Resumption of sexual relations following childbirth: norms, practices and reproductive health issues in Abidjan, Côte d'Ivoire. Reprod Health Matters. 2005;13(25):155-163.

29. Alum AC, Kizza IB, Osingada CP, Katende G, Kaye DK. Factors associated with early resumption of sexual intercourse among postnatal women in Uganda. Reprod Health. 2015;12:107.

30. Anzaku A, Mikah S. Postpartum resumption of sexual activity, sexual morbidity and use of modern contraceptives among nigerian women in jos. Ann Med Health Sci Res. 2014;4(2):210-216.

31. Adanikin AI, Awoleke JO, Adeyiolu A, Alao O, Adanikin PO. Resumption of intercourse after childbirth in southwest Nigeria. Eur J Contracept Reprod Health Care. 2015;20(4):241-248.

32. Soliman MH. Impact of antenatal counselling on couples' knowledge and practice of contraception in Mansoura, Egypt. East Mediterr Health J. 1999;5(5):1002-13.

33. Smith KB, van der Spuy ZM, Cheng L, Elton R, Glasier AF. Is postpartum contraceptive advice given antenatally of value? Contraception. 2002;65(3):237-243.

34. Akman M, Tüzün S, Uzuner A, Başgul A, Kavak Z. The influence of prenatal counselling on postpartum contraceptive choice. J Int Med Res. 2010;38(4):1243-1249.

35. Ayiasi RM, Muhumuza C, Bukenya J, Orach CG. The effect of prenatal counselling on postpartum family planning use among early postpartum women in Masindi and Kiryandongo districts, Uganda. Pan Afr Med J. 2015;21:138. 
36. Adanikin AI, Onwudiegwu U, Loto OM. Influence of multiple antenatal counselling sessions on modern contraceptive uptake in Nigeria. Eur J Contracept Reprod Health Care. 2013;18(5):381-387.

37. Foreit KG, Foreit JR, Lagos G, Guzman A. Effectiveness and costeffectiveness of postpartum IUD insertion in Lima, Peru. Int Fam Plann Perspect. 1993;19(1):19-33.

38. Blumenthal PD, Shah NM, Jain K, et al. Revitalizing long-acting reversible contraceptives in settings with high unmet need: a multicountry experience matching demand creation and service delivery. Contraception. 2013;87(2):170-175.

39. Pleah T, Hyjazi Y, Austin S, et al. Increasing use of postpartum family planning and the postpartum IUD: early experiences in West and Central Africa. Glob Health Sci Pract. 2016;4(Suppl 2):S140-S152.

40. Bolam A, Manandhar DS, Shrestha P, Ellis M, Costello AM. The effects of postnatal health education for mothers on infant care and family planning practices in Nepal: a randomised controlled trial. $B M J$. 1998;316(7134):805-811.

41. Saeed GA, Fakhar S, Rahim F, Tabassum S. Change in trend of contraceptive uptake--effect of educational leaflets and counseling. Contraception. 2008;77(5):377-381.

42. Tawfik Y, Rahimzai M, Ahmadzai M, Clark PA, Kamgang E. Integrating family planning into postpartum care through modern quality improvement: experience from Afghanistan. Glob Health Sci Pract. 2014;2(2):226-233.

43. Shaaban OM, Hassen SG, Nour SA, Kames MA, Yones EM. Emergency contraceptive pills as a backup for lactational amenorrhea method (LAM) of contraception: a randomized controlled trial. Contraception. 2013;87(3):363-369.

44. Vernon R, Lopez-Canales JR, Carcamo JA, Galindo J. The impact of a perinatal reproductive health program in Honduras. Int Fam Plann Perspect. 1993;19(3):103-109.
45. Abdel-Tawab N, Loza S, Zaki A. Helping Egyptian women achieve optimal birth spacing intervals through fostering linkages between family planning and maternal/child health services. In: Population Council, ed. Washington DC: Frontiers in Reproductive Health; 2008. Available from: http://pdf.usaid.gov/pdf_docs/PNADN580.pdf.

46. Ahmed S, Ahmed S, McKaig C, et al. The Effect of Integrating Family Planning with a Maternal and Newborn Health Program on Postpartum Contraceptive Use and Optimal Birth Spacing in Rural Bangladesh. Stud Fam Plann. 2015;46(3):297-312.

47. Bossyns P, Miyé H, Vlerberghe W. Supply-level measures to increase uptake of family planning services in Niger: the effectiveness of improving responsiveness. Trop Med Int Health. 2002;7(4):383-390.

48. Huntington D, Aplogan A. The integration of family planning and childhood immunization services in Togo. Stud Fam Plann. 1994;25(3): 176-183.

49. Cooper C, Fields R, Taylor N, et al. Final assessment report: Integration of Expanded Program on Immunization and Family Planning in Liberia. Available from: https://www.mchip.net/sites/default/files/Liberia $\% 20$ EPI\%20FP\%20Integration\%20Final\%20Assessment\%20Report.pdf. Accessed April 5, 2018.

50. Vance G, Janowitz B, Chen M, et al. Integrating family planning messages into immunization services: a cluster-randomized trial in Ghana and Zambia. Health Policy Plan. 2014;29(3):359-366.

51. Dulli LS, Eichleay M, Rademacher K, Sortijas S, Nsengiyumva T. Meeting Postpartum Women's Family Planning Needs Through Integrated Family Planning and Immunization Services: Results of a Cluster-Randomized Controlled Trial in Rwanda. Glob Health Sci Pract. 2016;4(1): $73-86$.
Open Access Journal of Contraception

\section{Publish your work in this journal}

Open Access Journal of Contraception is an international, peerreviewed, open access, online journal, publishing original research, reports, reviews and commentaries on all areas of contraception. In addition to clinical research, demographics and health-related aspects, the journal welcomes new findings in animal and preclinical studies

\section{Dovepress}

relating to understanding the biological mechanisms and practica development of new contraceptive agents. The manuscript management system is completely online and includes a very quick and fair peer-review system. Visit http://www.dovepress.com/testimonials.php to read real quotes from published authors. 